\title{
MJMR MACHIAVELLIANISM, EXPRESSIVE SUPPRESSION AND INTERNALIZING BEHAVIORS OF ADOLESCENTS IN UCSI INTERNATIONAL SCHOOL
}

\author{
Roshanak Zarei Mahmood Abadi*, Amira Najiha Binti Yahya, Mohtaram Rabbani \\ Department of Psychology, Faculty of Social Sciences \& Liberal Arts, UCSI University, Kuala Lumpur \\ Malaysia \\ *Corresponding Author: zareiroshanak@gmail.com
}

\begin{abstract}
The current study examines the associations of Machiavellianism(Mach) and Expressive Suppression(ES) as explanations for internalizing behaviors. This study aimed to examine Mach in adolescents with internalizing behaviors, and to explore the mediating role of ES in the relation between Mach and internalizing behaviors. Youth Self Report (YSR), Mach-IV scale alongside with the Emotion Regulation Questionnaire for Children and Adolescents (ERQ-CA) was administered to 104 adolescents in UCSI International University with the age range of 13-18. Pearson correlation coefficients as well as standard mediational analysis was executed to test the stated hypothesis. It was concluded that Mach was positively correlated with internalizing behaviors in adolescents attending UCSI International University. It was drawn that ES partially mediates the indirect relationship between Mach and anxious/depressive symptoms while it fully mediates the relationship between Mach and Depressed/Withdrawn.
\end{abstract}

Keywords: Adolescents, Emotion Regulation, Internalizing Behaviors, Machiavellianism

\section{INTRODUCTION}

Adolescence is known to be a stage of experiencing intense changes, conflicts and challenges, as the period of transition into adulthood (Arnett, 1999). Susman \& Rogol (2004) highlighted the intercorrelation among biological, social and psychological factors in adolescents' development. It is reported that considerable number of adolescents might experience conflictual interpersonal relationships (Hashim, 2007), develop developmental problems such as depression and suicide (Berk, 2017) and in general face with increasing number of emotional and behavioral problems (Idris,2017). Besides, social changes due to the urbanization in Malaysia have led to intensification of mental health problems in children and adolescents in Malaysia (Idris, 2017).

Recognizing how critical this development considered to be for the adolescents' subsequent years of life, increasing number of literature have been studying the components associated with internalizing and externalizing behaviors in Malaysia (Salwina et al., 2013; Ahmad et al.,2015; Kaur et al., 2014; Nik Jaafar et al., 2013; Low et al.,2018) which might interfere with normal development of the adolescents. Internalizing behaviours, which are the focus of this study, indicate to introverted psychological problems such as depressed and anxious symptoms, social withdrawal and somatic complaints (Achenbach \& Edelbrock, 1983; Liu, 2004).

Machiavellianism (Mach) and Expressive Suppression (ES) are presumed to be two socio-cognitive components which can significantly affect mental health in children and adolescents (Mash \& Berkley, 1998). Deficits in mental health results in impairments in individual's interpersonal relations and therefore, might lead to manifestation of disorders. In order to address this issue, it is suggested to examine social, affective and cognitive functions (Seppala, Rossomando \& Doty, 2013).

Machiavellianism (Mach) is regarded as socialbehavioural pathway in which an individual tends to deceive others with an ulterior motive of personal gain and interest (Wilson, Near \& Miller, 1996). Some studies have investigated the relevant components to Machiavellianism. For instance, negative association between Mach and emotional intelligence in both sample of adults and children have been reported. 
Second, some researchers focused on the association between ToM and Mach. Controversial results were found. While positive relation between cognitive Tom and Mach was presented (Chandler, Fritz \& Hala, 1978; Russell et al., 1991), in a study conducted by 'Barlow, Qualter \& Stylianou (2010), Mach was investigated as an extra correlate of ToM. The results showed a negative correlation between ToM and Mach. Additionally, negative correlation between emotional intelligence (i.e. trait and ability) and Mach was found which was divergent with previous literature (Austin et al., 2007).

Emotion Regulation is a process in which individual identifies the emotion, evaluates the emotion and eventually modifies the affective response in a specific situation and it consists of extrinsic and intrinsic process (langevin, Hebert \& Cosstette, 2015). Deficits in ER is referred as emotion dysregulation which is highly correlated to great number of psychological disorders. In specific, internalizing disorders such as depression and anxiety (Gross,1998). It is stated that children with internalized disorders experience emotions in different fashion comparing to their peers. Negative and threatening information is believed to be intensified in such individuals. Expressive Suppression (ES) and Cognitive Reappraisal are the emotion regulation strategies used by individuals in confrontation with different emotional cues. This study highlights Expressive Suppression in association with internalizing behaviours in adolescents. This study aims to examine (1) the influence of Mach on Internalizing Behaviours; (2) Whether ES Mediates the relationship between Mach and Internalizing Behaviours.

\section{LITERATURE REVIEW}

Coming into conflicts with parents and teachers, experiencing mood swings, tendencies of risky behaviours expand in adolescence (Arnett, 1999; Buchanan \& Holmbeck, 1998). Taken from the teachers and parents perspectives, adolescence is assumed to be a challenging period for young adults. Therefore, Several studies proclaimed that Internalizing Behaviours in adolescence is dramatically intensified comparing to early- or middle-childhood periods (Wenar \& Kerig, 2006; Buchanan \& Holmbeck, 1998). Internalizing Behaviours is defined as intropunitive disturbed moods and emotions which is composed of behavioural, cognitive and affective aspects (Zhan-Waxler, Dougan, \& Slattery; 2000).

In the past decades, considerable amount of attention has drawn to the socio-cognitive components (Machiavellianism, Emotion Regulation) associated to internalizing behaviours in children and adolescents. In a longitudinal seminal research executed by Geng et al. (2017), the associations between Machiavellianism, internalizing and externalizing behaviors in 454 Chinese adolescents were examined. Several outcomes were found. First, it was asserted that the most apparent levels of Mach is found in youth and in subsequent stages of life it decrease slightly. This was consistent with the previous work (Sutton \& Keogh, 2000). Second, Machiavellianism was reported to be positively correlated with psychological problems (i.e. hyperactivity, emotional symptoms, peer relationship and conduct problems). Several existing findings were in line with the former (Geng et al., 2016; Lau \& Marsee, 2013; Muris, Meester 2013). Lastly, Geng et al. (2017) failed to support the hypothesis in which internalizing behaviors played a mediating role between Mach and externalizing behaviors.

Emotion regulation is defined as a process in which an individual monitor, evaluates and modulates the emotional responses in pursuance of accomplishing personal objectives and enhancing social functioning (Thompson, 1994). More awareness over affective functions will be gained in adolescence comparing to the childhood. However, due to the intensified nature of such components, less control is observed among adolescents (Casey, Jones \& Hare, 2008).

The process model of emotion regulation developed by Gross (1998) in the past recent years and it received a considerable amount of attention among developmental researchers (Betts, Gullone, \& Allen, 2009, Hughes et al., 2006, Larsen et al., 2013). This model aims to highlight different emotion regulation strategies one can employ within the process of generating emotions. Antecedent-focused (i.e. cognitive reappraisal) or response-focused (i.e. expressive suppression) strategies might regulate the perceived emotion (Gross, 1998).

The most comprehensive and coherent body of research involving internalizing behaviors has consistently 
highlighted the role of emotion regulation. However, the findings over that topic are still sparse and vague. Some studies have demonstrated suppressing negative emotions might be linked to later internalizing and externalizing disorders in children and adolescents (Keenan \& Hipwell, 2005; Eisenberg, Spinrad \& Eggum, 2000; Cole, Michel \& Teti, 1994). In a study of school-age girls by Keenan \& Hipwell (2005), depressive symptoms were associated with those who suppressed their negative emotions.

It is true that, the main variables of current study have been individually studied. However, to our knowledge, no research has been carried out inspecting all the discussed variables. Therefore, by conducting his research we are with this hope that we can fill the literature gap specifically in Malaysian context.

\section{RESULTS AND DISCUSSION}

\section{Participants}

The participants are chosen by employing nonprobability convenience sampling in UCSI International University. 104 adolescents were chosen within the age range of 13-18.

\section{Measures}

\section{Youth Self Report (YSR)}

YSR (Achenbach, 1991) with a total items of 112, is a self-administered instrument for the children with the age range of 11-18. It aims at identifying externalizing and internalizing difficulties over the past six month with a 3point-Likert score $(0=$ not true; $1=$ somewhat/sometimes true; $2=$ very/often true). The internalizing band pertains to anxious/depressed, somatic complaints and social withdrawal. Higher scores indicate to higher internalizing behaviours in adolescents. The internalizing band has shown an excellent reliability of internal consistency with the Cronbach alpha of 0.92 (Alati et al., 2005)

\section{The Mach IV}

The Mach IV (Christie \& Geis, 1970), measures levels of Machiavellianism in children (deception) while using the 5-point Likert scoring (1=strongly agree to $5=$ strongly disagree). In overall, the survey comprises of 20 items (e.g. "the best way to handle people is to tell them what they want to hear"). Higher scores represent higher Machiavellianism. Rauthmannn (2013) claimed an acceptable internal consistency for the kiddie Mach $(\alpha=0.82)$.

The Emotion Regulation Questionnaire for Children and Adolescents (ERQ-CA)

ERQ-CA is a revised version of the Emotion Regulation Questionnaire (ERQ) developed. It consists of 10 simplified items. The items' wordings are simplified in ERQ-CA. Furthermore, the seven-point Likert scoring is reduced to five-point Likert scoring ( $1=$ strongly disagree, $2=$ disagree, $3=$ half and half, 4=agree, 5= strongly agree). ERQ-CA assess Emotion Regulation strategies of Cognitive reappraisal (6 items: i.e. "When I want to feel happier, I think about something different") and Expressive suppression (4 items: i.e. "I keep my feelings to myself"). Higher scores in ERQ-CA shows greater Emotion regulation strategies in individuals. Internal consistency for both domains has been reported high with $\alpha=0.79$ (Cognitive reappraisal) and $\alpha=0.73$ (Expressive Suppression). Comparingly, past literature proclaims a high 3-month test-retest reliability $(r=$ 0.69). Additionally, the discriminant and convergent validity were reported good. Scoring range for Cognitive Reappraisal was 6-30 while the scoring range for the Expressive Suppression was 4-20 (Gross \& John, 2004).

\section{Analysis}

Prior to conducting any statistical analysis, data should be prepared. Hence, data cleaning, screening for missing data, outliers, normality and multicollinearity was carefully executed. Statistical Package for the Sal Sciences version 19.0 (SPSS 19.0) is believed to be the major statistical instrument, were utilized in the analyses of the current research.

Descriptive Analysis- The preliminary information including participants' demographic profile and the constructs of present study is depicted using in table 1 . The majority of the participants were $15-16$ years old (52.9\%) while 17-18 year-olds were the least (14.4\%) $(\mathrm{M}=15.8, \mathrm{Sd} .=1.2)$. Female and Male participants were equally distributed $(\mathrm{f}=50 \%, \mathrm{~m}=50 \%)$. The majority of respondents were Chinese $(74.7 \%)$, Others $(13.5 \%)$, Indian (7.7\%) and Malay (4.8\%), respectively. 
Table 1: Sample Characteristics of Respondents

\begin{tabular}{|l|l|l|l|l|l|l|}
\hline Variables & $\boldsymbol{n}$ & $\mathbf{\%}$ & Mean & Sd. & Min & Max \\
\hline Age(years) & & & 15.08 & 1.2 & 13 & 17 \\
\hline $13-14$ & 34 & 32.7 & & & & \\
\hline $15-16$ & 55 & 52.9 & & & & \\
\hline $17-18$ & 15 & 14.4 & & & & \\
\hline Sex & & & & & & \\
\hline Male & 52 & 50.0 & & & & \\
\hline Female & 52 & 50.0 & & & & \\
\hline Race & & & & & & \\
\hline Malay & 5 & 4.8 & & & & \\
\hline Chinese & 77 & 74.7 & & & & \\
\hline Indian & 8 & 7.7 & & & & \\
\hline Others & 14 & 13.5 & & & & \\
\hline
\end{tabular}

Differences in mean scores by sex and age of adolescents are displayed in Table 2. Accordingly, adolescents with age range of 13-14 demonstrated higher levels of Machiavellianism $58.90(\mathrm{SD}=1.319)$ comparing to those in the late adolescent stage. Moreover, Anxious/ Depressive and Withdrawn/Depressive behaviors were significantly higher in adolescents between 17-18 respectively $(\mathrm{M}=11.87, \mathrm{SD}=1.1951 ; \mathrm{M}=7.80, \mathrm{SD}=$ 6.41). However, Emotional Suppression was slightly fluctuated in all age groups with the mean of 12.97 (SD $=0.365$ ) for youngsters in their early stage of adolescence , 12.71 (SD =0.290) in mid stage of adolescence and $12.73(\mathrm{SD}=0.473)$ in late stage of adolescence, emphasizing that emotional suppression as a kind of emotion regulation strategy, is much more implemented in early adolescent years comparing to adolescents with the age range of 15-18.

Table 2: Means and Standard Deviation of Main Variables by Sex and Age

\begin{tabular}{|l|c|c|c|c|c|}
\hline Variables & $\begin{array}{c}\text { Female } \\
\text { Mean } \\
\text { (SD) }\end{array}$ & $\begin{array}{c}\text { Male } \\
\text { Mean } \\
\text { (SD) }\end{array}$ & $\begin{array}{c}\mathbf{1 3 - 1 4} \\
\text { Mean } \\
\text { (SD) }\end{array}$ & $\begin{array}{c}\mathbf{1 5 - 1 6} \\
\text { Mean } \\
\text { (SD) }\end{array}$ & $\begin{array}{c}\mathbf{1 7 - 1 8} \\
\text { Mean } \\
\text { (SD) }\end{array}$ \\
\hline Mach-IV & $\begin{array}{c}57.98 \\
(0.979)\end{array}$ & $\begin{array}{c}57.75 \\
(0.929)\end{array}$ & $\begin{array}{c}58.90 \\
(1.319)\end{array}$ & $\begin{array}{c}57.47 \\
(0.927)\end{array}$ & $\begin{array}{c}56.80 \\
(1.118)\end{array}$ \\
\hline ERQ-CA & $\begin{array}{c}13.00 \\
(0.277)\end{array}$ & $\begin{array}{c}12.60 \\
(0.302)\end{array}$ & $\begin{array}{c}12.97 \\
(0.365)\end{array}$ & $\begin{array}{c}12.71 \\
(0.290)\end{array}$ & $\begin{array}{c}12.73 \\
(0.473)\end{array}$ \\
\hline YSR & \multicolumn{5}{|l}{} \\
\hline Anx/Dep & 12.17 & 8.60 & 10.03 & 10.20 & 11.87 \\
& $(0.839)$ & $(0.725)$ & $(1.184)$ & $(0.753)$ & $(1.195)$ \\
\hline Wit/ Dep & 6.63 & 5.25 & 5.50 & 5.71 & 7.80 \\
& $(0.464)$ & $(0.422)$ & $(0.638)$ & $(0.406)$ & $(6.41)$ \\
\hline Som/Com & 5.35 & 4.21 & 4.38 & 5.16 & 4.27 \\
& $(0.476)$ & $(0.489)$ & $(0.626)$ & $(0.474)$ & $(0.825)$ \\
\hline
\end{tabular}

Note: Anx/Dep: Anxious/Depressed, Wit/Dep: Withdrawn/Depressed, Som/Com: Somatic
This finding is parallel to outcomes by Gullone \& Taffe (2011). Levels of Machiavellianism, Emotional Suppression and Internalizing Behaviors (i.e. Anxious /Depressive, Withdrawn/Depressive and Somatic Complains) were significantly higher in females. This finding is inconsistent with the past findings, where males reported with higher total levels of Machiavellianism (Barlow, Quarter \& Stylianou, 2010).

Bivariate Analysis-Bivariate relationships among the study variables were described using Pearson Correlation Coefficients (Table 3). Results revealed that Machiavellianism is positively associated with Depressed/Anxious $(r=0.305, P<0.01)$, Withdraw $/$ Depressed $(r=0.211, P<0.05)$ and Somatic Complaints $(r=0.220, P<0.05)$. In other words, Machiavellianism and Internalizing behaviours demonstrate a low to moderate positive correlation. The findings obtained through previous studies were consistent with the findings of the present study (Geng et al., 2017).

\section{Table 3: Pearson Correlations for All Key Measures}

\begin{tabular}{|l|l|l|l|l|l|}
\hline & 1 & 2 & 3 & 4 & 5 \\
\hline Mach-Iv & 1 & & & & \\
\hline Emotional Suppression & $0.217^{*}$ & 1 & & & \\
\hline Depressed/Anxious & $0.305^{* *}$ & $0.294^{* *}$ & 1 & & \\
\hline Withdrawn/Depressed & $0.211^{*}$ & $0.208^{*}$ & $0.721^{* *}$ & 1 & \\
\hline Somatic Complaints & $0.220^{*}$ & $0.212^{*}$ & $0.561^{* *}$ & $0.443^{* *}$ & 1 \\
\hline$P<.01^{* *}, P<.05^{*}$ & & &
\end{tabular}

It can be gleaned from Table 3 that, Emotional suppression is positively associated to other study variables; with a low positive correlation to Machiavellianism ( $r=0.217, P<0.01)$, Anxious/ Depressive behaviours $(r=0.294, P<0.01)$, Withdrawn /Depressive behaviours $(r=0.208, P<0.05)$, and Somatic Complains $(r=0.212, P<0.05)$. There are insufficient studies on the relationship between Machiavellianism and Emotional Suppression. However, Expressive Suppression and Cognitive Reappraisal are defined as strategies used in emotion regulation (Gullone \& Taffe, 2011) and that emotion regulation is considered as a subset of Emotional Intelligence (Jaworowska \& Matczak, 2001). Therefore, it is suspected that the provided findings respecting emotional intelligence might indicate to emotional intelligence. Inconsistent with the results of the current study, previous findings demonstrated a negative relationship between 
Machiavellianism and emotional intelligence (Pilch, 2008; Sjöberg et al., 2001; Austin et al., 2007). Furthermore, the demonstrated relationships between Expressive Suppression and internalizing behaviours were similar to previous research findings (Larsen et al.,2013; Keenan \& Hipwell, 2005; Eisenberg, Spinrad \& Eggum 2000; Cole, Michael \& Teti, 1994).

Standard Mediational Analysis- The aim of this section is to examine the mediating role of Expressive Suppression on the between Machiavellianism and Internalizing Behaviors. Multicollinearity was not a problem $(\mathrm{VIF}=1.049$; tolerance $=0.953)$. With regards to Anxious/Depressed, in model 1 of the hierarchical regression, Machiavellianism was significantly related to Anxious/ Depressive Behaviors [F (1.102) $=10.493, p$
$<0.01]$. When Expressive Suppression was added in model 3, Mach became less significant $[\mathrm{F}(1.102)=5.019$, $p<0.05]$ and Expressive Suppression was significantly related to Anxious/Depressive behaviors [F $(2,102)$ $=8.751, p<0.001]$. Thus, Expressive Suppression appeared to partially mediate the relation between Machiavellianism and Anxious Depressive behaviors (Table 4.). The following regression coefficient were presented: Expressive Suppression on Anxious/ depressed $(\beta=0.239, p<0.05)$, and Anxious/Depressed on Mach and Expressive Suppression $(\beta=0.254, p<0.01)$. Results of Sobel's test were significant $(z=0.634 ; p<$ 0.01 ), with approximately $16.7 \%$ of the Mach to Anxious/Depressed path accounted for by Expressive Suppression (Figure 1).

Table 4: Standard Mediational Analysis for Anxious Depressed

\begin{tabular}{|c|c|c|c|c|c|c|c|c|c|c|}
\hline & \multicolumn{2}{|c|}{$\begin{array}{l}\text { Unstand. } \\
\text { Coefficients }\end{array}$} & \multirow{2}{*}{$\begin{array}{l}\begin{array}{l}\text { Stan. } \\
\text { Coefficie } \\
\text { nts }\end{array} \\
\beta\end{array}$} & \multirow[b]{2}{*}{$r^{2}$} & \multirow[b]{2}{*}{$t$} & \multirow[b]{2}{*}{ Sig. } & \multicolumn{2}{|c|}{$\begin{array}{l}\text { 95\% Confidence } \\
\text { Interval }\end{array}$} & \multicolumn{2}{|c|}{$\begin{array}{l}\text { Collinearity } \\
\text { Statistics }\end{array}$} \\
\hline & B & $\mathrm{SE}(\mathrm{B})$ & & & & & $\begin{array}{l}\text { Lower } \\
\text { Bound }\end{array}$ & $\begin{array}{l}\text { Upper } \\
\text { Bound }\end{array}$ & $\begin{array}{l}\text { Tolerance } \\
\text { Value }\end{array}$ & VIF \\
\hline \multicolumn{11}{|l|}{ Model 1} \\
\hline $\begin{array}{l}\text { Mach } \\
\rightarrow \text { Anx/Dep }\end{array}$ & 0.639 & 0.197 & 0.305 & 0.093 & 3.239 & 0.002 & 0.248 & 1.021 & 1.00 & 1.00 \\
\hline \multicolumn{11}{|l|}{ Model 2} \\
\hline Mach $\rightarrow$ Sup & 0.161 & 0.072 & 0.217 & 0.047 & 2.240 & 0.027 & 0.018 & 0.303 & 1.00 & 1.00 \\
\hline Model 3 & & & & 0.148 & & & & & & \\
\hline Mach & 0.531 & 0.197 & 0.254 & & 2.696 & 0.008 & 0.140 & 0.922 & 0.953 & 1.049 \\
\hline Sup & 0.675 & 0.266 & 0.239 & & 2.539 & 0.013 & 0.148 & 1.202 & 0.953 & 1.049 \\
\hline
\end{tabular}

Note: Model 1: $\mathrm{F}(1,102)=10.493, \mathrm{p}<.01 ;$ Model 2: $\mathrm{F}(1,102)=5.019, \mathrm{P}<0.05 ;$ Model 3: $\mathrm{F}(2,102)=8.751, \mathrm{P}<.001$.

1

C
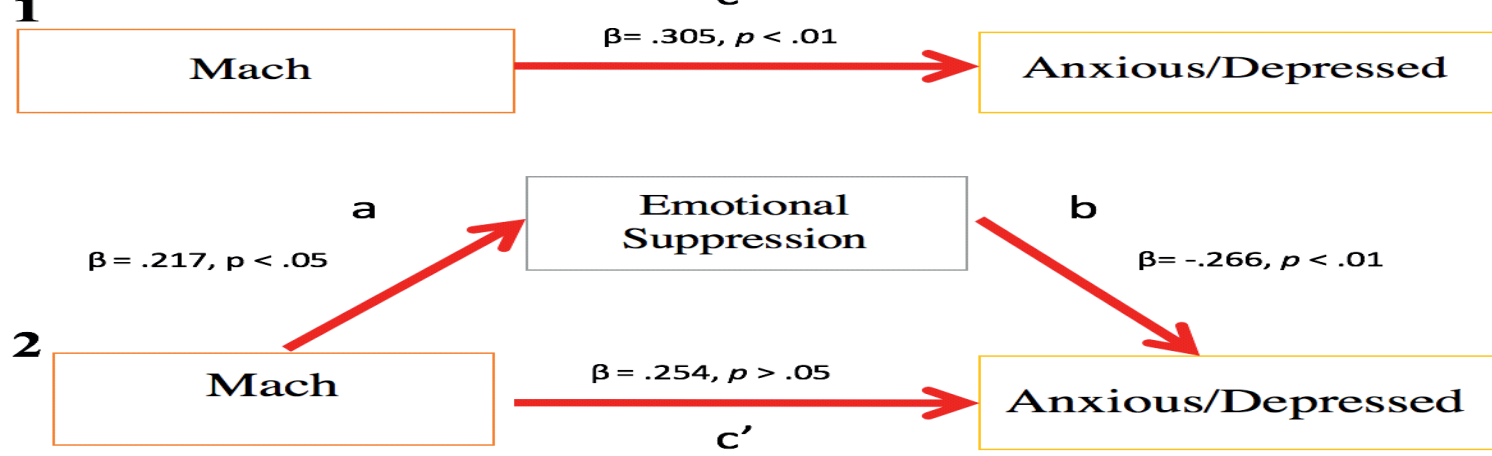

Figure1: Results of the standard meditational analysis 
It can be drawn that the significance in path $\mathrm{c}$ and c' has decreased while the relationship in path $b$ is still significant; presenting the partial mediation.

With respect to withdrawn/depressed, in model 1 of the hierarchical regression, Machiavellianism was significantly related to Depressed/Withdrawn Behaviors $[\mathrm{F}(1.102)=4.771, P<0.05]$. When Expressive Suppression was added in model 3, Mach became insignificant $[\mathrm{F}(1.102)=5.019, p<0.05]$ and Expressive Suppression was significantly related to Depressed / Withdrawn behaviors $[\mathrm{F}(2.102)=8.751, p$
$<0.001]$. Thus, Expressive Suppression appeared to fully mediate the relation between Machiavellianism and Depressed/Withdrawn behaviors (Table 5). The following regression coefficient were presented: Expressive Suppression on Withdrawn/Depressed $(\beta=$ $0.170, p<0.05)$, and Withdrawn/Depressed on Mach and Expressive Suppression $(\beta=0.175, P>0.05)$. Results of Sobel's test were significant $(z=1.339 ; p<0.05)$, with approximately $13.9 \%$ of the Mach to Withdrawn/ Depressed path accounted for by Expressive Suppression (Figure 2).

Table 5: Standard Mediational Analysis for Withdrawn/Depressed

\begin{tabular}{|c|c|c|c|c|c|c|c|c|c|}
\hline \multicolumn{3}{|l|}{$\begin{array}{l}\text { Unstand. } \\
\text { Coefficients }\end{array}$} & \multirow{2}{*}{$\begin{array}{l}\text { Stan. } \\
\text { Coefficie } \\
\text { nts } \\
\beta\end{array}$} & \multirow[b]{2}{*}{$t$} & \multirow[b]{2}{*}{ Sig. } & \multicolumn{2}{|c|}{$\begin{array}{l}\text { 95\% Confidence } \\
\text { Interval }\end{array}$} & \multicolumn{2}{|c|}{$\begin{array}{l}\text { Collinearity } \\
\text { Statistics }\end{array}$} \\
\hline B & \multicolumn{2}{|c|}{$\mathrm{SE}(\mathrm{B})$} & & & & $\begin{array}{l}\text { Lower } \\
\text { Bound }\end{array}$ & $\begin{array}{l}\text { Upper } \\
\text { Bound }\end{array}$ & $\begin{array}{l}\text { Tolerance } \\
\text { Value }\end{array}$ & VIF \\
\hline \multicolumn{10}{|l|}{ Model 1} \\
\hline $\begin{array}{l}\text { Mach } \\
\rightarrow \text { With/Dep }\end{array}$ & 0.244 & 0.112 & 0.211 & 2.184 & 0.031 & 0.022 & 0.466 & 1.00 & 1.00 \\
\hline \multicolumn{10}{|l|}{ Model 2} \\
\hline Mach $\rightarrow$ Sup & 0.161 & 0.072 & 0.217 & 2.240 & 0.027 & 0.018 & 0.303 & 1.00 & 1.00 \\
\hline \multicolumn{10}{|l|}{ Model 3} \\
\hline Mach & 0.202 & 0.113 & 0.175 & 1.778 & 0.078 & 0.023 & 0.427 & 0.953 & 1.049 \\
\hline Sup & 0.265 & 0.153 & 0.170 & 1.730 & 0.027 & 0.039 & 0.568 & 0.953 & 1.049 \\
\hline
\end{tabular}

Note: Model 1: $\mathrm{F}(1,102)=4.771, \mathrm{P}<.0 .05 ;$ Model 2: $\mathrm{F}(1,102)=5.019, \mathrm{P}<.05 ;$ Model $3: \mathrm{F}(2,101)=3.928, \mathrm{P}<.05$,

1

C

\section{Mach}

$\beta=.211, p<.05$

\section{Withdrawn/Depressed}

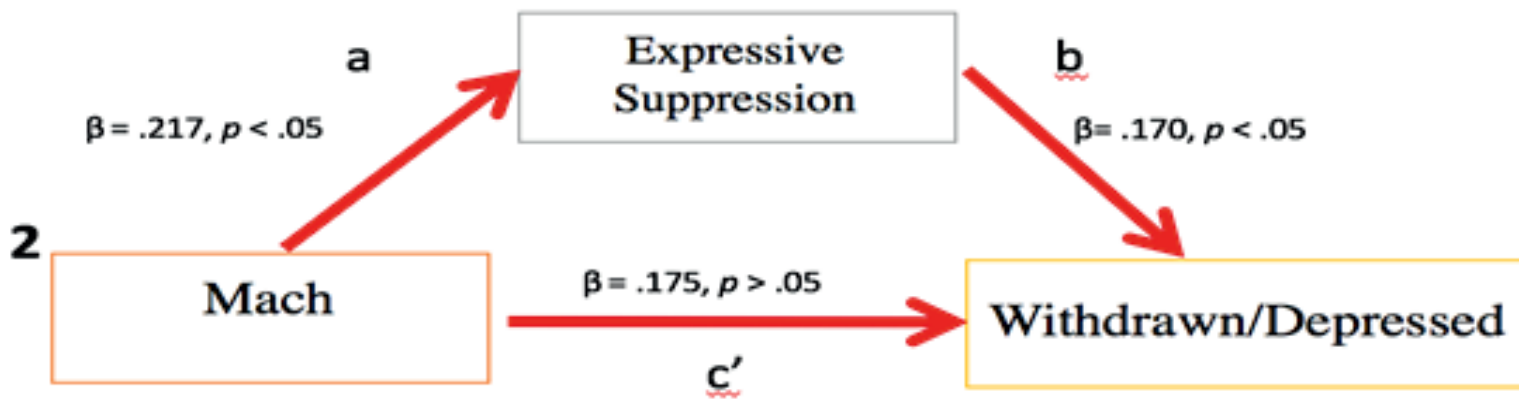

Figure 2: Results of the standard meditational analysis 
It can be illustrated that the significance in path c and c' has shifted to insignificant while the relationship in path b is still significant; presenting the full mediation.

Regarding Somatic complains, the model 1 of the hierarchical regression, Machiavellianism was significantly related to Somatic Complaints [F (1.102) $=$ 5.191, $P<0.05]$. When Expressive Suppression was added in model 3, Mach became more significant
$[\mathrm{F}(1.102)=5.019]$ and Expressive Suppression was insignificant to Somatic Complaints [F (2.101) $=2.571$, $P>0.05]$. Thus, Expressive Suppression appeared not to mediate the relation between Machiavellianism and Somatic Complains (Table 6). The following regression coefficient were presented: Expressive Suppression on Somatic Complaints $(\beta=0.970, p>0.05)$ and Withdrawn/Depressed on Mach and Expressive Suppression $(\beta=0.029, P<0.05)$.

Table 6: Result for Mediational Analysis- Somatic Complains

\begin{tabular}{|c|c|c|c|c|c|c|c|c|c|}
\hline & \multicolumn{2}{|c|}{$\begin{array}{l}\text { Unstand. } \\
\text { Coefficients }\end{array}$} & \multirow{2}{*}{$\begin{array}{l}\text { Stan. } \\
\text { Coefficients } \\
\beta\end{array}$} & \multirow[b]{2}{*}{$t$} & \multirow[b]{2}{*}{ Sig. } & \multicolumn{2}{|c|}{$\begin{array}{l}95 \% \text { Confidence } \\
\text { Interval }\end{array}$} & \multicolumn{2}{|c|}{$\begin{array}{l}\text { Collinearity } \\
\text { Statistics }\end{array}$} \\
\hline & B & $\mathrm{SE}(\mathrm{B})$ & & & & $\begin{array}{l}\text { Lower } \\
\text { Bound }\end{array}$ & $\begin{array}{l}\text { Upper } \\
\text { Bound }\end{array}$ & $\begin{array}{l}\text { Tolerance } \\
\text { Value }\end{array}$ & VIF \\
\hline \multicolumn{10}{|l|}{ Model 1} \\
\hline $\begin{array}{l}\text { Mach } \rightarrow \\
\text { Som Com }\end{array}$ & 0.274 & 0.120 & 0.220 & 2.278 & 0.025 & 0.035 & 0.512 & 1.00 & 1.00 \\
\hline \multicolumn{10}{|l|}{ Model 2} \\
\hline $\begin{array}{l}\text { Mach } \rightarrow \\
\text { Sup }\end{array}$ & 0.161 & 0.072 & 0.217 & 2.240 & 0.027 & 0.018 & 0.303 & 1.00 & 1.00 \\
\hline \multicolumn{10}{|l|}{ Model 3} \\
\hline Mach & 0.275 & 0.124 & 0.221 & 2.221 & 0.029 & 0.079 & 0.520 & 0.953 & 1.049 \\
\hline Sup & 0.006 & 0.167 & 0.004 & 0.037 & 0.970 & 0.337 & 0.325 & 0.953 & 1.049 \\
\hline
\end{tabular}

Note: Model I: $\mathrm{F}(1,102)=5.191, \mathrm{P}<.05 ;$ Model 2: $\mathrm{F}(1,102)=5.019, \mathrm{P}<.05 ;$ Model 3: $\mathrm{F}(2,101)=2.571, \mathrm{P}>.05$.

The purpose of this section was to investigate the mediating role of expressive suppression as a component of emotion regulation, in the relationship of the Machiavellianism and internalizing behaviors (i.e. Anxious/Depressed, Depressed/Withdrawn and Somatic Complaints). From the previous results, it indicates that the total effect of the Mach on Anxious/Depressed $(\beta=$ $0.305, p<0.01$ ) decreases when suppression is included in the model $(\beta=0.254, p<0.050)$. Moreover, the indirect effect of Mach on Anxious/Depressed through Expressive Suppression is significant as examined by Sobel test $(z=1.67, P<0.01)$. The direct effect of Mach on Anxious/Depressed decreases but it is significant. Therefore, Expressive Suppression is a partial mediator of the relation between Mach and Anxious/Depressed.

Furthermore, it indicates that the total effect of the Mach on Withdrawn/Depressed $(\beta=0.211, p<0.05)$ is no longer significant when suppression is included in the model $(\beta=0.175, p>0.05)$. Moreover, the indirect effect of Mach on Withdrawn/Depressed through Expressive Suppression is significant as examined by Sobel test $(z=$ $1.33, P<0.05$ ). Therefore, Expressive Suppression is a full mediator of the relation between Mach and Withdrawn/Depressed.

Lastly, it is seemed that the total effect of the Mach on Withdrawn/Depressed $(\beta=0.220 p<0.05)$ is no longer significant when suppression is included in the $\operatorname{model}(\beta$ $=0.221, p<0.05)$. Therefore, Emotional Suppression is not a mediator of the relation between Mach and Somatic Complain.

The findings of the current study are homogenous with the previous studies. Machiavellians-individuals who have high scores on Mach scales-display a specific emotion regulation style (Christie \& Geis, 1970). 
Furthermore, emotion dysregulation has been indicated to mediate the association among stress exposure and negative psychological health outcomes. This single out the mediating role of emotion regulation in internalizing behaviors. In an explicit study by Deak et al. (2017), it was asserted that cognitive reappraisal mediates the relationship between Machiavellianism and neurooncological levels.

Moreover, Sharp et al., (2011) claimed that two components of emotion regulation (i.e. cognitive reappraisal and expressive suppression mediate the relationship between affective theory of mind and adolescents with borderline personality traits. According to the past studies, affective theory of mind is an analogous term with Machiavellianism as they are linked with comprehending emotion and expressing them in a literal or a deceptive trend (Dennis et al., 2013). Therefore, it can be said from previous statements that the findings of the present study demonstrate a consistent result with the reviewed literature in general.

\section{CONCLUSION AND RECOMMENDATION}

The result of this study needs to be considered in the light of number of limitations. First, this is a cross-sectional study, which limits any casual inferences. According the Bandura (1999), the interplay among personal factors and exhibition of behaviors are dynamic. Therefore, conducting a longitudinal study where the casual relationship of the former factors can be fully investigated might be essential in further studies. Moreover, the small sample size in this study might have affected the results of the current study (Cresswell, 2007). Thus, taking a greater sample size might demonstrate a more significant result. Besides, the main focus of this study was on adolescents within the age range of 13-18. A comparable study on earlier stages of life (i.e. early, mid or late childhood) can be conducted in future research. Plus, concentrating on a clinical sample rather than nonclinical sample might lead to a more considerable result. Lastly, employing multiple sources rather than counting on merely a source, is considered to be another recommendation for the following studies.

\section{ACKNOWLEDGEMENT}

No funding was received in this study. The authors declared no conflict of interest. The study procedure followed the standard research ethical standard of UCSI University Kuala Lumpur.

\section{REFERENCES}

Achenbach, T. M. (1991). Integrative Guide for the CBCL/418, YSR and TRF Profiles. University of Vermont, USA

Achenbach, T.M., \& Edelbrock, C. (1983). Manual for the Behavior Problem Checklist and Revised Child Behavior Profile. Burlington, VT: Queen City Printers.

Ahmad, N., Muhd Yusoff, F., Ratnasingam, S., Mohamed, F., Nasir, N. H., Mohd Sallehuddin, S., Naidu, B.M., Ismail, R.\& Aris, T. (2015). Trends and Factors Associated with Mental Health Problems Among Children And Adolescents In Malaysia. International Journal of Culture and Mental Health, 8(2), pp 125-136

Alati, R., O'Callaghan, M., Najman, J. M., Williams, G. M., Bor, W. \& Lawlor, D. A. (2005). Asthma and Internalizing Behavior Problems in Adolescence: A Longitudinal Study. Psychosomatic Medicine, 67(3), pp 462-470.

Arnett, J. J. (1999). Adolescent Storm and Stress, Reconsidered. American Psychologist, 54(5), pp 317-326

Austin, E. J., Farrelly, D., Black, C. \& Moore, H. (2007). Emotional Intelligence, Machiavellianism, and Emotional Maniupulation: Does EI Have A Dark Side? Personality and Individual Differences, 43(1), pp 179-189.

Bandura, A. (1999). A social cognitive theory of personality. Guilford Publications, USA

Barlow, A., Qualter, P. \& Stylianou, M. (2010). Relationships between Machiavellianism, emotional intelligence and theory of mind in children. Personality and Individual Differences, 48(1), pp 78-82.

Berk, L. E. (2017). Development Through the Lifespan. $7^{\text {th }}$ Edition, Pearson Education, UK

Betts, J., Gullone, E. \& Allen, J. S. (2009). An Examination of Emotion Regulation, Temperament, And Parenting Style s Potential Predictors of Adolescent Depression Risk Status: A Correlational Study. British Journal of Developmental Psychology, 27(Pt 2), pp 473-485.

Buchanan, C.M. \& Holmbeck, G. N. (1998). Measuring Beliefs About Adolescent Personality and Behavior. Journal of Youth and Adolescence 
27(5), pp 607-627

Casey, B. J., Jones, R. M. \& Hare, T. A. (2008). The Adolescent Brain. Annals of the New York Academy of Sciences, 1124(1), pp 111-126.

Chandler, M., Fritz, A. S. \& Hala, S. (1989). SmallScale Deceit: Deception as a Marker of Two-, Three-And Four-Year-Olds' Early Theories of Mind. Child Development, 60(6), pp 1263-1277.

Christie, R. \& Geis, F.L. (1970). Studies in Machiavellianism. Academic Press, USA

Cole, P. M., Michel, M. K. \& Teti, L. O. (1994). The Development of Emotion Regulation And Dysregulation: A Clinical Perspective. Monographs of the Society for Research in Child Development, 59(2-3), pp 73-102.

Creswell, J. W. (2007). Qualitative Inquiry \& Research Design: Choosing Among Five Approaches, $2^{\text {nd }}$ Edition, Sage,USA

Deak, A., Bodrogi, B., Biro, B., Perlaki, G., Orsi, G.\& Bereczkei, T.(2017). Machiavellian emotion regulation in a cognitive reappraisal task: An fMRI study.Cognitive, Affective \& Behavioral Neuroscience, 17(3), pp 528-541

Dennis, M., Simic, N., Bigler, E. D., Abildskov, T., Agostino, A., Taylor, H. G., Rubin, K., Vannatta, K., Gerhardt, C.A., Stancin, T. \& Yeates, K. O. (2013). Cognitive, Affective, and Conative Theory of Mind (Tom) In Children with Traumatic Brain Injury. Developmental Cognitive Neuroscience, 5, pp 25-39.

Eisenberg, N., Spinrad, T. L., \& Eggum, N. D. (2010). Emotion-Related Self-Regulation and Its Relation to Children's Maladjustment. Annual Review of Clinical Psychology, 6, pp 495-525.

Geng, Y. G., Chang, G., Li, L., Zhang, R., Sun, Q. \& Huang, J. (2016). Machiavellianism In Chinese Adolescents: Links to Internalizing and Externalizing Problems. Personality and Individual Differences, 89, pp 19-23.

Geng, Y., Yang, Z., Zhang, R., Fan, W., Yan, F., Sai, X., \& Liu, Y. (2017). Relations Between Machiavellianism, Internalizing and Externalizing Behavior Problems in Adolescents: A One-Year Longitudinal Study. Personality and Individual Differences, 119, pp 296-300.

Gross, J. J. \& John, O. P. (2003). Individual Differences in Two Emotion Regulation Processes: Implications for Affect, Relationships, and WellBeing. Journal of Personality and Social Psychology, 85(2), 348-362.

Gross, J.J. (1998). The Emerging Field of Emotion Regulation: An Integrative Review. Review of General Psychology, 2(3), pp 271-299.

Gullone, E. \& Taffe, J. (2011). The Emotion Regulation Questionnaire for Children and Adolescents (ERQ-CA): A Psychometric Evaluation. Psychological Assessment, pp 1-9

Hashim, I. (2007). Stress, Coping and Social Supports in the Adolescent Years. Kajian Malaysia, 25(1), pp 97-115

Hughes, C., Fujisawa, K. K., Ensor, R., Lecce, S. \& Marfleet, R. (2006). Cooperation and Conversations About the Mind: A Study of Individual Differences in 2-Year-Olds and Their Siblings. British Journal of Developmental Psychology, 24, pp 53-72.

Idris, I.B. (2017). Emotional and Behavioural Problems among Children: Issues and Trends in Malaysia. International Journal of Public Health Research, 7(2), pp 829-835

Jaworowska, A. \& Matczak, A. (2001). Kwestionariusz Inteligencji Emocjonalnej INTE. [Emotional Intelligence Questionnaire INTE]. Warszawa: Pracownia Testów Psychologicznych PTP.

John, O. P. \& Gross, J. J. (2004). Healthy and Unhealthy Emotion Regulation: Personality Processes, Individual Differences, and Life Span Development. Journal of Personality, 72(6), pp 1301-1334.

Kaur, J., Cheong, S. M., Mahadir, N. B., Kaur, G., Manickam, M. A., Mat Noor, M., Ibrahim, N.\& Rosman, A. (2014). Prevalence and Correlates of Depression Among Adolescents in Malaysia. Asia Pacific Journal of Public Health, 26(5 suppl), pp $53 \mathrm{~S}-62 \mathrm{~S}$

Keenan, K. \& Hipwell, A. E. (2005). Preadolescent Clues to Understanding Depression In Girls. Clinical child and family psychology review, 8(2), pp 89-105.

Langevin, R., Hebert, M. \& Cossette, L. (2015). Emotion Regulation as a Mediator of the Relation Between Sexual Abuse and Behaviour Problems in PreSchoolers. Child Abuse \& Neglect, 46, pp 16-26.

Larsen, J., Ainsworth, E., Harrop, C., Patterson, S., 
Hamilton, S., Szymczynska, P., Tew, J., Manthorpe, J. \& Pinfold, V. (2013). Implementing Personalisation for People with Mental Health Problems: A Comparative Case Study of Four Local Authorities in England. Journal of Mental Health, 22(2), pp 174-182.

Lau, K. S. L. \& Marsee, M. A. (2013). Exploring Narcissism, Psychopathy, and Machiavellianism in Youth: Examination of Associations with Antisocial Behavior and Aggression. Journal of Child and Family Studies, 22(3), pp 355-367.

Liu J. (2004). Childhood Externalizing Behavior: Theory and Implications. Journal of child and adolescent psychiatric nursing, 17(3), pp 93-103.

Low, S.K., Tan, S.A., Kok, J.K, Nainee, S. \& Viapude, G. N. (2018). The Mental Health of Adolescent Refugees in Malaysia. PEOPLE: International Journal of Social Sciences, 4(2), pp 428-439.

Mash, E. J., \& Barkley, R. A. (Eds.). (1998). Treatment of childhood disorders. $2^{\text {nd }}$ Edition, Guilford Press, USA

Muris, P., Meesters, C. \& Timmermans, A. (2013). Some Youth Have A Gloomy Side: Correlates of the Dark Triad Personality Traits in Non-Clinical Adolescents. Child Psychiatry and Human Development, 44(5), pp 658-665.

Nik Jaafar, N. R., Tuti Iryani, M. D., Wan Salwina, W. I., Fairuz Nazri, A. R., Kamal, N. A., Prakash, R. J. \& Shah, S. A. (2013). Externalizing and Internalizing Syndromes in Relation to School Truancy Among Adolescents in High-Risk Urban Schools. Asia-Pacific Psychiatry, 5, pp 27-34.

Pilch, I. (2008). Machiavellianism, emotional intelligence and social competence: Are Machiavellians interpersonally skilled? Polish Psychological Bulletin, 39(3), 158-164.

Rauthmann, J. F.(2013). Investigating the MACH-IV with Item Response Theory and Proposing the Trimmed MACH. Journal of Personality Assessment, pp 1-10

Russell, J., Mauthner, N., Sharpe, S. \& Tidswell, T. (1991). The 'Windows Task' As A Measure of Strategic Deception in Preschoolers and Autistic Subjects. British Journal of Developmental Psychology, 9(2)

Salwina, WI, W., Ruzyanei, NJ, N., Nurliza, AM., Irma, AM., Hafiz, B., Ayob, I., Lew, KX., Shariff, MR,
R.\& Iryani, MD, T. (2013). Emotional and Behavioural Problems among Adolescent Offsprings of Mothers with Depression. Malaysian Journal of Medicine and Health Sciences,9(2), pp $35-43$

Seppala, E., Rossomando, T. \& Doty, J. R. (2013). Social Connection and Compassion: Important Predictors of Health and Well-Being. Social Research: An International Quarterly. 80 (2), pp 411-430.

Sharp, C., Pane, H., Ha, C., Venta, A., Patel, A.B., Sturek, J. \& Fonagy, P. (2011). Theory of Mind and Emotion Regulation Difficulties in Adolescents with Borderline Traits. Journal of the American Academy of Child and Adolescent Psychiatry, 50(6), pp 563-573.

Sjoberg, L.(2001).Emotional Intelligence: A Psychometric Analysis. European Psychologist, 6(2), pp 79-95

Susman, E. J., \& Rogol, A. (2004). Puberty and psychological development. In R. M. Lerner \& L. Steinberg (Eds.), Handbook of adolescent psychology (pp. 15-44). Hoboken, NJ, US: John Wiley \& Sons Inc.

Sutton, J. \& Keogh, E. (2000). Social competition in school: Relationships with bullying, Machiavellianism and personality. The British Journal of Educational Psychology, 70(Pt 3), pp 443-456

Thompson, R. A. (1994). Emotion regulation: A theme in search of definition. Monographs of the Society for Research in Child Development, 59(2/3), pp 25-52

Wenar, C. \& Kerig, P. (2006). Developmental psychopathology: from infancy through adolescence. Retrieved from: file:///C:/Users/LUCKOL/Desktop/Kerigposter.pdf

Wilson, D. S., Near, D. \& Miller, R. R. (1996). Machiavellianism: A Synthesis of The Evolutionary and Psychological Literatures. Psychological Bulletin, 119(2), pp 285-299.

Zahn-Waxler, C., Klimes-Dougan, B. \& Slattery, M. (2000). Internalizing Problems of Childhood and Adolescence: Prospects, Pitfalls, and Progress in Understanding the Development of Anxiety and Depression. Development and Psychopathology, 12(3), pp 443-466. 